\title{
Absence of consistent sex differences in outcomes from symptomatic carotid endarterectomy and stenting randomized trials
}

Virginia J. Howard, PhD, Department of Epidemiology, School of Public Health, University of Alabama at Birmingham, Birmingham, AL

Ale Algra, MD, Department of Neurology and Neurosurgery, Brain Center Rudolf Magnus and Julius Center for Health Sciences and primary Care, University Medical Center Utrecht and Utrecht University, Utrecht, the Netherlands

George Howard, DrPH, Department of Biostatistics, School of Public Health, University of Alabama at Birmingham, Birmingham, $\mathrm{AL}$

Leo H. Bonati, MD, Stroke Research Centre, Department of Brain Repair and Rehabilitation, UCL Queen Square Institute of Neurology, University College London, London, UK and Department of Neurology and Stroke Center, Department of Clinical Research, University Hospital Basel, University of Basel, Basel, Switzerland

Gert J. de Borst, MD, Department of Vascular Surgery, University Medical Center Utrecht, Utrecht University, Utrecht, the Netherlands

Richard Bulbulia, MD, Clinical Trial Service Unit and Epidemiological Studies Unit (CTSU), and MRC Population Health Research Unit, Nuffield Department of Population Health, University of Oxford, UK

David Calvet, MD, Department of Neurology, Hopital Sainte-Anne, Universite ParisDescartes, DHU Neurovasc Sorbonne Paris Cite, INSERM U894, Paris, France 
Hans-Henning Eckstein, MD, Department of Vascular and Endovascular

Surgery/Vascular Center, Klinikum rechts der Isar der Technischen Universitat Munchen,

Munich, Germany

Gustav Fraedrich, MD, Department of Vascular Surgery, Medical University of

Innsbruck, Austria

Jacoba Greving, PhD, Julius Centre for Health Sciences and Primary Care, University

Medical Centre Utrecht and Utrecht University, Utrecht, the Netherlands

Alison Halliday, MD, Nuffield Department of Surgical Sciences, John Radcliffe Hospital,

Oxford, UK

Jeroen Hendrikse, MD, Department of Radiology, University Medical Center Utrecht,

Utrecht, the Netherlands

Olav Jansen, MD, PhD, Clinic for Radiology and Neuroradiology, UKSH Campus Kiel,

Kiel, Germany

Martin M. Brown, MD, Stroke Research Centre, Department of Brain Repair and Rehabilitation, UCL Queen Square Institute of Neurology, University College London, London, UK

Jean-Louis Mas, MD, Department of Neurology, Hopital Sainte-Anne, Universite ParisDescartes, DHU Neurovasc Sorbonne Paris Cite, INSERM U894. Paris, France

Peter A Ringleb, MD, Department of Neurology, University of Heidelberg Medical School, Heidelberg, Germany

Thomas G. Brott, MD, Department of Neurology, Mayo Clinic, Jacksonville, FL on behalf of the Carotid Stenosis Trialists' Collaboration 
Corresponding Author: Virginia J. Howard, Department of Epidemiology, University of Alabama School of Public Health, RPHB 210F, $15303^{\text {rd }}$ Avenue S, Birmingham, AL 352940022, USA vjhoward@uab.edu

Cover title: Sex differences in CAS-CEA Treatment Effect

Tables: 2

Figures: 2

Supplemental Figure: 1

Key words: carotid stenosis, endarterectomy, stents, sex differences, stroke, revascularization, women

Subject terms: cerebrovascular disease/stroke, cerebrovascular procedures, stenosis, revascularization, stent

Word count: $\quad 4,672$ 
Abstract

\section{Background and Purpose}

The Carotid Revascularization Endarterectomy vs. Stenting Trial (CREST) reported a higher periprocedural risk for any stroke, death, or myocardial infarction for women randomized to carotid artery stenting (CAS) compared to women randomized to carotid endarterectomy (CEA). No difference in risk by treatment was detected for women relative to men in the 4-year primary outcome. We aimed to conduct a pooled analysis among symptomatic patients in large randomized trials to provide more precise estimates of sex differences in the CAS-to-CEA risk for any stroke or death during the 120-day periprocedural period and ipsilateral stroke thereafter.

\section{Methods}

Data from the Carotid Stenosis Trialists' Collaboration included outcomes from symptomatic patients in EVA-3S, SPACE, ICSS and CREST. The primary outcome was any stroke or death within 120-days after randomization and ipsilateral stroke thereafter. Event rates and relative risks were estimated using Poisson regression; effect modification by sex was assessed with a sex-by-treatment-by-trial interaction term, with significant interaction defined a priori as $\mathrm{p} \leq$ 0.10 .

\section{Results}

Over a median 2.7 years of follow-up, 433 outcomes occurred in 3,317 men and 1,437 women. The CAS-to-CEA relative risk of the primary outcome was significantly lower for women compared to men in one trial, nominally lower in another, and nominally higher in the other two . The sex-by-treatment-by-trial interaction term was significant $(\mathrm{p}=0.065)$, indicating 
heterogeneity among trials. Contributors to this heterogeneity are primarily differences in periprocedural period. When the trials are nevertheless pooled, there were no significant sex differences in risk in any follow-up period.

\section{Conclusions}

There were significant differences between trials in the magnitude of sex differences in treatment effect (CAS-to-CEA relative risk), indicating it is inappropriate to pool data from these trials to estimate sex differences. Whether sex is acting as an effect modifier of the CAS-to-CEA treatment effect in symptomatic patients remains uncertain.

Clinical Trial Registration URL: $\underline{\text { https://www.clinicaltrials.gov; http://www.isrctn.com }}$ Unique identifier: NCT00190398 (EVA-3S), NCT00004732 (CREST), ISRCTN57874028 (SPACE), and ISRCTN25337470 (ICSS) 


\section{Introduction}

Several clinical trials have assessed whether sex may modify the treatment effect of carotid artery stenting (CAS) versus carotid endarterectomy (CEA). In a pre-specified subgroup analysis of patients with $\geq 70 \%$ carotid bifurcation stenosis, the Carotid Revascularization Endarterectomy vs. Stenting Trial (CREST) reported a higher periprocedural risk for any stroke, myocardial infarction, or death for women randomized to carotid artery stenting (CAS) compared to women randomized to carotid endarterectomy (CEA), with little difference for men. However, there was no evidence of a relative difference in the 4-year primary composite endpoint that included only ipsilateral stroke after the periprocedural period. ${ }^{1}$ The International Carotid Stenting Study (ICSS) found borderline significance for a sex difference in periprocedural risk: for symptomatic patients, women had similar risk following CAS or CEA, but men had a higher risk with CAS compared to CEA. ${ }^{2}$ There was no significant sex difference in the long-term outcome in ICSS. ${ }^{3}$ No significant treatment differences by sex were found for either the periprocedural period or the long-term follow-up in the Stent-Protected Angioplasty versus Carotid Endarterectomy in Symptomatic Patients (SPACE) trial. ${ }^{4,5}$

The Carotid Stenosis Trialists' Collaboration (CSTC) is an international collaboration of investigators from major clinical trials focused on contrasting the efficacy of CAS and CEA in symptomatic and asymptomatic patients. This collaboration conducted a meta-analysis of individual patient data combining three trials of patients with symptomatic carotid stenosis: the Endarterectomy versus Angioplasty in Patients with Symptomatic Severe Carotid Stenosis (EVA-3S), SPACE, and ICSS. Sex was included among several factors where interaction between the effect of treatment on the primary outcome was examined, and there was no 
difference by sex in the relative risk of any stroke or death within 120 days in patients randomized to CAS or CEA. ${ }^{6}$

CREST joined the CSTC since its first publication ${ }^{6}$ and provides an additional 1,321 patients to the original 3,433 analysis cohort of symptomatic patients. This $38 \%$ increase includes 466 women and 855 men. Thus, the purpose of this analysis was to conduct a pooled analysis of the CSTC data to provide a more precise estimate of sex as an effect modifier of the CAS-to-CEA treatment effect in symptomatic patients overall, and separately for the periprocedural (120 days) and post-procedural period.

\section{Methods}

These analyses use individual patient-level data from the four completed revascularization trials that included symptomatic patients: EVA-3S (NCT 00190398), SPACE (ISRCTN 57874028), ICSS (ISRCTN 25337470) and CREST (NCT00004734.) Each of the trials were reviewed and approved by the appropriate ethics committee and all patients provided written informed consent. Although CREST enrolled both symptomatic and asymptomatic patients, only data from patients with symptomatic arteries were included herein. Requests for anonymized data supporting these analyses should be submitted to Leo.Bonati@usb.ch representing the CSTC Steering Committee. Enrollment for all trials began in 2000-2001 with discontinuation of EVA-3S in 2005 and SPACE in 2006, and completion of ICSS and CREST in 2008. Median follow-up time was 7 years in EVA-3S, 4 years in ICSS, 3 years in CREST, and 2 years in SPACE.

Baseline clinical characteristics by sex groups were compared within each trial. The primary outcome was any stroke or death during the periprocedural period (within 120 days of 
randomization) and ipsilateral stroke during the post-procedural period. For each trial, we calculated Kaplan-Meier survival curves of treatment and sex differences in risk. Analyses were intention-to-treat. Results were reported for the entire follow-up period and for the periprocedural and post-procedural periods separately. Poisson regression was used to estimate sex-specific treatment event rates per-person-year (PPY) for each trial. These rates were used to calculate the CAS-to-CEA treatment efficacy, quantified by the CAS-to-CEA relative risk with $95 \%$ confidence intervals. Sex differences in treatment efficacy were reported by the women/men (W/M) ratio (with $95 \%$ confidence intervals) of the sex-specific relative risk. In the absence of significant interaction, we intended to do an analysis of the pooled data from the four trials with event rate estimates adjusted for age group ( $<70$ years versus $\geq 70$ years $)$ and source trial while estimates from each individual trial were adjusted only for age group. The consistency of the treatment effect between the trials was assessed by interaction terms with significant interaction defined a priori as $\mathrm{p} \leq 0.10$, reflecting heterogeneity. When there is evidence of substantial heterogeneity, the Cochrane guidelines for meta-analyses recommend presenting only the individual study results and suppressing the pooled estimates $;{ }^{7}$ however, we choose to present the pooled estimates with appropriate cautionary comment about interpretation.

\section{Results}

Of the total 4,754 symptomatic patients across the four trials, 1,437 (30\%) were women, ranging from $25 \%$ in EVA-3S to $35 \%$ in CREST (Table 1). The average age of the patients was approximately 70 years. There was substantial variation in the prevalence of risk factors between trials, e.g., dyslipidemia in less than $60 \%$ of patients in EVA-3S but above $75 \%$ of patients in CREST. With few exceptions, differences between the sexes within trials were 
relatively small, e.g. in all trials, men had higher prevalence of coronary heart disease than women; in all trials but ICSS there was a higher prevalence of diabetes in women than men.

A total of 433 events (335 during the periprocedural period and 98 during the postprocedural period) occurred over a median follow-up of 2.7 years (interquartile range 2.0 to 4.5 years). Estimates of the CAS-to-CEA primary and other treatment outcomes, and sex differences in those outcomes are numerated in Table 2. Figures 1A through 1D provide the Kaplan-Meier estimates of event rates for the four trials. As detailed below, compared to men, the CAS-toCEA relative risk of the primary outcome in women was significantly lower in one trial, nominally lower in one trial, and nominally higher in the other two trials.

\section{Analysis of the Primary Outcome (Periprocedural and Post-Procedural period)}

In EVA-3S (Figure 1A) the CAS-to-CEA relative risk for women was 0.58 (95\% CI: 0.20 - 1.66), while for men it was 2.39 (95\% CI: $1.21-4.69)$, with a significant difference by sex $(\mathrm{W} / \mathrm{M}$ ratio $=0.24 ; 95 \% \mathrm{CI}: 0.07-0.84)$. In contrast, in SPACE (Figure 1B), the CAS-to-CEA relative risk for women was 1.44 (95\% CI: 0.68 - 3.05), and 1.01 (95\% CI: $0.67-1.53)$ for men, with a non-significant W/M ratio of $1.43 ; 95 \% \mathrm{CI}$ : $0.61-3.37$. ICSS had a similar pattern to EVA-3S (i.e., lower risk in women than men), but the sex difference did not reach statistical significance, with a W/M ratio of $0.62(95 \% \mathrm{CI}: 0.32-1.20)$. CREST results were similar to SPACE with a higher CAS-to-CEA relative risk in women than men that was not statistically significant (W/M ratio of 1.30 ; $95 \% \mathrm{CI}: 0.58-2.91)$. With the W/M ratio of CAS-to-CEA risk lower for women than men in EVA-3S and ICSS, but higher for women than men in SPACE and CREST, there was evidence of inconsistency in the impact of sex across trials $(p=0.065)$. This 
heterogeneity is shown graphically in supplemental Figures IA and IB (Please see https://www.ahajournals.org/journal/str).

While the original goal of this study was to pool data across trials to provide a more precise estimate of sex differences in CAS-CEA treatment efficacy, this is not appropriate because of the heterogeneity between trials. ${ }^{7}$ However, we show the pooled event rates by sex and treatment assignment in Figure 2, with a CAS-to-CEA risk ratio of 1.31 (95\% CI: $0.94-$ 1.83) for women, and 1.52 (95\% CI: $1.21-1.93)$ for men. There was no evidence of difference in these ratios $(\mathrm{RR}=0.86 ; 95 \% \mathrm{CI}: 0.57-1.29 ; \mathrm{p}=0.47)$ (Table 2$)$.

\section{Analysis of the Periprocedural Period}

The pattern of the 120-day periprocedural period risk shows a similar pattern to the overall analysis (Table 2), specifically that the CAS-to-CEA relative risk was lower in women than men in EVA-3S and ICSS (W/M ratio of $0.39 ; 95 \%$ CI: $0.10-1.60$ and $0.51 ; 95 \%$ CI: 0.23 - 1.15, respectively), but higher in women than men in SPACE and CREST (W/M ratio of 1.54; 95\% CI: $0.63-3.78$ and 1.51; 95\% CI: $0.58-3.95$, respectively).

The test for consistency across trials was slightly above the a priori threshold for statistical significance $(\mathrm{p}=0.13)$, with a pooled CAS-to-CEA relative risk of $1.57(95 \% \mathrm{CI}: 1.06$ $-2.31)$ for women and 1.70 (95\% CI: $1.30-2.22)$ for men; there was no evidence of a difference in these risk ratios $(\mathrm{RR}=0.93 ; 95 \% \mathrm{CI}: 0.58-1.48 ; \mathrm{p}=0.75)($ Table 2$)$.

\section{Analysis of the Post-Procedural Period}

Table 2 provides the similar analysis of the post-procedural CAS-to-CEA risk by sex. With only $98(23 \%)$ events during the post-procedural period across all trials, results for this 
period should be interpreted with caution. The interpretation is further complicated by the fact that there were no events during the post-procedural period for women treated with CAS in either EVA-3S or SPACE; with no events, the CAS-CEA relative risk cannot be calculated for women. In ICSS, the CAS-to-CEA relative risk was similar for women (1.26; 95\% CI: 0.52 3.05) and men (1.34; $95 \%$ CI: $0.67-2.71)$ with a W/M ratio of $0.93 ; 95 \% \mathrm{CI}: 0.30-2.88)$. It was also similar for women and men in CREST (0.72; 95\% CI: $0.23-2.28$ and 0.34 ; 95\% CI: $0.07-1.66$, respectively) with a W/M ratio of $2.15(0.30-15.45)$.

The test for consistency across trials was not statistically significant $(\mathrm{p}=0.46)$, and the pooled estimate of the CAS-to-CEA relative risk was 0.81 (95\% CI: $0.42-1.55)$ for women and 1.04 (95\% CI: $0.63-1.71)$ for men, with no evidence of a difference by sex in these ratios $(\mathrm{RR}=$ 0.78; 95\% CI: $0.34-1.77 ; \mathrm{p}=0.55)($ Table 2).

\section{Discussion}

There were significant differences between the trials in the magnitude of sex differences in the treatment effect (CAS-to-CEA relative risk) that met our a priori threshold of statistical significance, i.e., $\mathrm{p}=0.065$ which is $\leq 0.10$. The Cochrane guidelines recommend that pooled analyses not be performed in the presence of significant heterogeneity between trials. ${ }^{7} \mathrm{We}$ nevertheless provided results from the pooled analyses to provide an overall estimate of the sex difference in treatment efficacy but advise caution in its interpretation. . Testing whether subgroup-treatment effect interactions differ between trials is an inexact science and there are differences of opinion among statisticians and epidemiologists. There was not a significant treatment difference for women in any of the trials. However, in EVA-3S and ICSS, compared to men randomized to CEA, men randomized to CAS were at higher risk of the primary 
outcome. In EVA-3S, this higher risk in men but not in women treated with CAS resulted in a significant sex difference in the CAS-to-CEA risk.

It is difficult to speculate what factors are contributing to the inconsistencies in outcomes by sex among trials. Specifically, for a risk factor to be playing a role, the pattern of sex differences in the risk factor between the trials would have to be similar to the pattern of sex differences in treatment effects. None of the risk factors examined had such a pattern.

Differences between the sexes that were not examined may contribute to the different results across the trials, e.g., timing of revascularization. ${ }^{8}$ In post hoc analysis of older CEA trials, with longer time from index stroke or TIA to procedure, women had significantly less benefit with no impact in men. ${ }^{9,} 10$ EVA 3 S, CREST and ICSS reported on the association of treatment effect with time from index event to revascularization; none presented results by sex groups, but CREST reported no difference by sex in time from index event to revascularization. ${ }^{2,3,11,12}$ Characteristics that are not available may also have contributed to the lack of consistent results across the trials, e.g., plaque characteristics such as plaque length, degree of stenosis, side of lesion and other angiographic characteristics. ${ }^{13-16}$ Other factors not available include expertise of the operators and technical details, hence we could not assess if potential differences in these factors contributed to treatment differences by sex. Finally, it is important to remember that these trials enrolled patients more than a decade ago and advances in technology may subsequently affect relative treatment efficacy.

Whether sex is acting as an effect modifier of the CAS-to-CEA treatment effect in symptomatic patients remains uncertain. Clinical trials are designed for a sample size to provide adequate statistical power to assess the main treatment effect, so by definition they are underpowered to assess if subgroups have different treatment effects, i.e., an interaction 
hypothesis (including the assessment of sex differences in efficacy). Precise and reliable estimates of subgroup differences will be reliant on either pooled analyses (as attempted herein) or meta-analyses of aggregate data. In considering multiple trials simultaneously, one must assume that the underlying treatment effect between the subgroups (in this case, between men and women) is consistent among the trials. This was, unfortunately, not the case for these analyses. Additional trials randomizing symptomatic patients with high-grade carotid stenosis to CAS versus CEA are unlikely to be mounted, so the role of sex as an effect modifier of the CAS-CEA treatment difference is likely to remain unanswered. 
Sources of Funding

Dr. Greving is supported by the Dutch Heart Foundation (grant number 2013T128). Dr.

Halliday's research is funded by the National Institute for Health Research. Oxford Biomedical

Research Center. Dr. Bonati received grants from the Swiss National Science Foundation

(PBBSB-116873), the University of Basel, Switzerland, and the Stroke Association, United

Kingdom. Dr. Bulbulia received funding from the UK Medical Research Council. Dr. Brown's

Chair in Stroke Medicine was supported by the Reta Lila Weston Trust for Medical Research.

Part of this work was undertaken at University College London, which received a proportion of

funding from the UK Department of Health's National Institute for Health Research Biomedical Research Centres funding scheme. Drs. VJ Howard, G Howard, and TG Brott were funded by the National Institutes of Health/National Institute of Neurological Disorders and Stroke (NIH/NINDS) U01 NS038384.

Disclosures

Dr. de Borst has received an advisory board fee from Bayer. Dr. Bonati has received an unrestricted research grant from AstraZeneca; consultancy or advisory board fees or speaker's honoraria from Amgen, Bayer, Bristol-Myers Squibb, Claret Medical, and InnovHeart; and travel grants from AstraZeneca and Bayer. Dr. Ringeleb has received advisory board fees or speaker's honoraria from Bayer, Boehringer Ingelheim, Daiichi Sankyo, and Pfizer. The other authors report no conflict.

Supplemental Materials

Online Figures IA and IB 
References

1. Howard VJ, Lutsep HL, Mackey A, Demaerschalk BM, Sam AD, 2nd, Gonzales NR, et al. Influence of sex on outcomes of stenting versus endarterectomy: A subgroup analysis of the carotid revascularization endarterectomy versus stenting trial (crest). Lancet neurology. 2011;10:530-537

2. International Carotid Stenting Study i, Ederle J, Dobson J, Featherstone RL, Bonati LH, van der Worp HB, et al. Carotid artery stenting compared with endarterectomy in patients with symptomatic carotid stenosis (international carotid stenting study): An interim analysis of a randomised controlled trial. Lancet. 2010;375:985-997

3. Bonati LH, Dobson J, Featherstone RL, Ederle J, van der Worp HB, de Borst GJ, et al. Long-term outcomes after stenting versus endarterectomy for treatment of symptomatic carotid stenosis: The international carotid stenting study (icss) randomised trial. Lancet. 2015;385:529-538

4. Stingele R, Berger J, Alfke K, Eckstein HH, Fraedrich G, Allenberg J, et al. Clinical and angiographic risk factors for stroke and death within 30 days after carotid endarterectomy and stent-protected angioplasty: A subanalysis of the space study. Lancet neurology. 2008;7:216-222

5. Eckstein HH, Ringleb P, Allenberg JR, Berger J, Fraedrich G, Hacke W, et al. Results of the stent-protected angioplasty versus carotid endarterectomy (space) study to treat symptomatic stenoses at 2 years: A multinational, prospective, randomised trial. Lancet neurology. 2008; 7:893-902

6. Carotid Stenting Trialists C, Bonati LH, Dobson J, Algra A, Branchereau A, Chatellier G, et al. Short-term outcome after stenting versus endarterectomy for symptomatic carotid stenosis: A preplanned meta-analysis of individual patient data. Lancet. 2010;376:10621073

7. Higgins JPT, Thomas J, Chandler J, Cumpston M, Li T, Page MJ, et al. (editors). Cochrane handbook for systematic review of interventions, version 6.0 (updated july 2019). Available from www.Training.Cochrane.Org/handbook. Accessed april 20, 2020.

8. Meershoek AJA, de Borst GJ. Timing of carotid intervention. Br J Surg. 2018;105:12311233

9. Rothwell PM, Eliasziw M, Gutnikov SA, Warlow CP, Barnett HJ. Sex difference in the effect of time from symptoms to surgery on benefit from carotid endarterectomy for transient ischemic attack and nondisabling stroke. Stroke; a journal of cerebral circulation. 2004;35:2855-2861

10. De Rango P, Brown MM, Leys D, Howard VJ, Moore WS, Paciaroni M, et al. Management of carotid stenosis in women: Consensus document. Neurology. 2013;80:2258-2268

11. Mas JL, Chatellier G, Beyssen B, Branchereau A, Moulin T, Becquemin JP, et al. Endarterectomy versus stenting in patients with symptomatic severe carotid stenosis. The New England journal of medicine. 2006;355:1660-1671

12. Meschia JF, Hopkins LN, Altafullah I, Wechsler LR, Stotts G, Gonzales NR, et al. Time from symptoms to carotid endarterectomy or stenting and perioperative risk. Stroke; a journal of cerebral circulation. 2015;46:3540-3542 
13. Doig D, Turner EL, Dobson J, Featherstone RL, de Borst GJ, Stansby G, et al. Risk factors for stroke, myocardial infarction, or death following carotid endarterectomy: Results from the international carotid stenting study. Eur J Vasc Endovasc Surg. 2015;50:688-694

14. Doig D, Turner EL, Dobson J, Featherstone RL, Lo RT, Gaines PA, et al. Predictors of stroke, myocardial infarction or death within 30 days of carotid artery stenting: Results from the international carotid stenting study. Eur J Vasc Endovasc Surg. 2016;51:327334

15. Moore WS, Popma JJ, Roubin GS, Voeks JH, Cutlip DE, Jones M, et al. Carotid angiographic characteristics in the crest trial were major contributors to periprocedural stroke and death differences between carotid artery stenting and carotid endarterectomy. Journal of vascular surgery. 2016;63:851-857, 858 e851

16. Voeks JH, Howard G, Roubin G, Farb R, Heck D, Logan W, et al. Mediators of the age effect in the carotid revascularization endarterectomy versus stenting trial (crest). Stroke; a journal of cerebral circulation. 2015;46:2868-2873 
Figure Legend:

Figures 1A to 1D: Event rates estimated via Kaplan-Meier techniques for the individual trials, shown by treatment and sex

Figure 2: Event rates estimated via Kaplan-Meier techniques for the pooled trials, shown by treatment and sex 

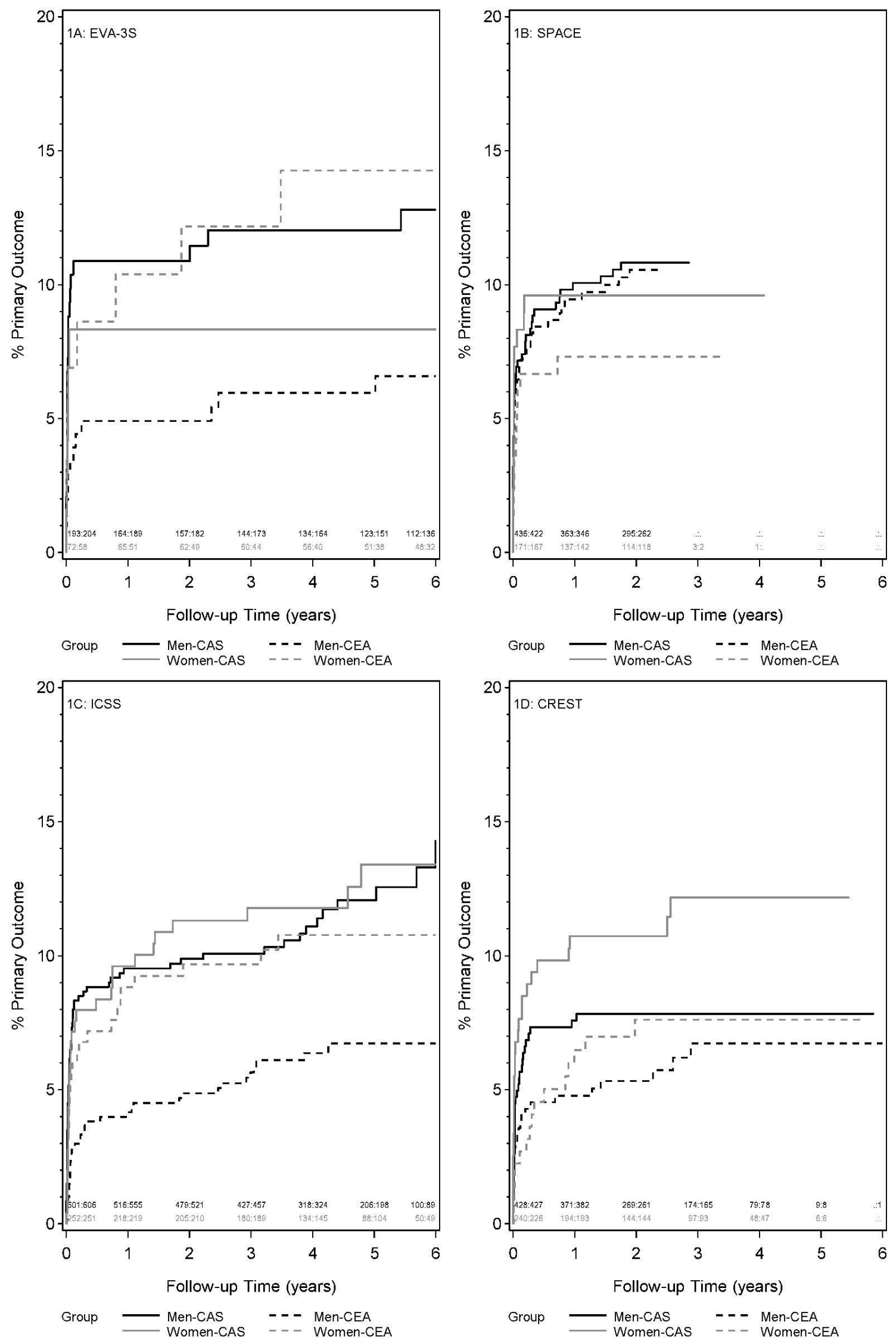


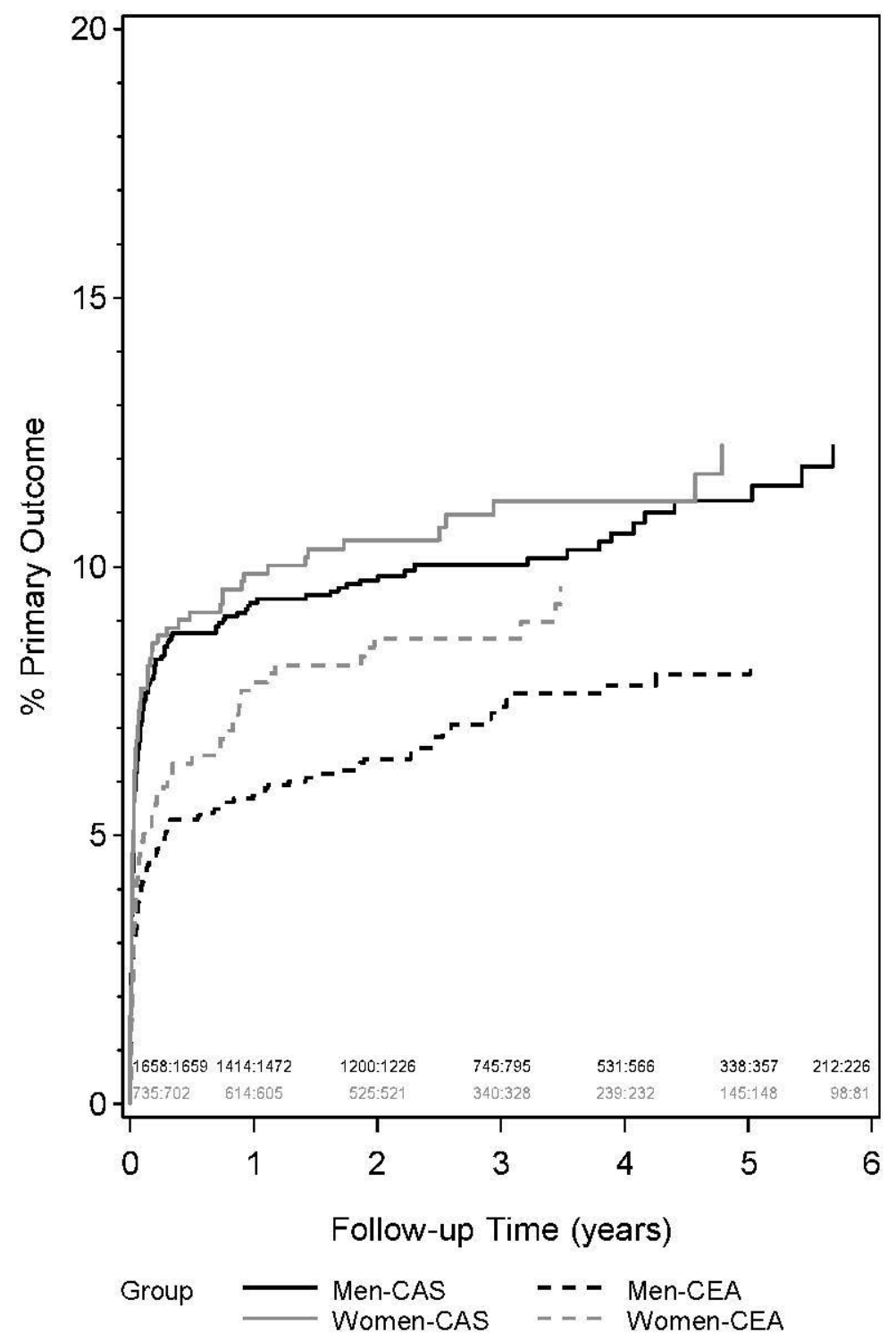


Table 1. Demographic and clinical characteristics.

\begin{tabular}{|c|c|c|c|c|c|c|c|c|}
\hline \multirow[t]{2}{*}{ Characteristic } & \multicolumn{2}{|c|}{$\begin{array}{l}\text { EVA-3S } \\
(n=527)\end{array}$} & \multicolumn{2}{|c|}{$\begin{array}{c}\text { SPACE } \\
(\mathrm{n}=1,196)\end{array}$} & \multicolumn{2}{|c|}{$\begin{array}{c}\text { ICSS } \\
(n=1,710)\end{array}$} & \multicolumn{2}{|c|}{$\begin{array}{c}\text { CREST } \\
(\mathrm{n}=1,321)\end{array}$} \\
\hline & $\begin{array}{l}\text { Women } \\
(\mathrm{n}=130)\end{array}$ & $\begin{array}{c}\text { Men } \\
(\mathrm{n}=397)\end{array}$ & $\begin{array}{l}\text { Women } \\
(\mathrm{n}=338)\end{array}$ & $\begin{array}{c}\text { Men } \\
(\mathrm{n}=858)\end{array}$ & $\begin{array}{l}\text { Women } \\
(\mathrm{n}=503)\end{array}$ & $\begin{array}{c}\text { Men } \\
(n=1207)\end{array}$ & $\begin{array}{l}\text { Women } \\
(\mathrm{n}=466)\end{array}$ & $\begin{array}{c}\text { Men } \\
(\mathrm{n}=855)\end{array}$ \\
\hline Age, mean (SD) & $\begin{array}{c}69.9 \\
(10.8)\end{array}$ & $\begin{array}{c}70.2 \\
(10.4)\end{array}$ & $\begin{array}{l}69.0 \\
(8.8)\end{array}$ & $\begin{array}{l}68.2 \\
(8.3)\end{array}$ & $\begin{array}{l}70.5 \\
(9.2)\end{array}$ & $\begin{array}{l}69.9 \\
(9.0)\end{array}$ & $\begin{array}{l}69.0 \\
(9.9)\end{array}$ & $\begin{array}{l}68.7 \\
(9.3)\end{array}$ \\
\hline Hypertension & $\begin{array}{c}98 / 130 \\
(75.4)\end{array}$ & $\begin{array}{c}285 / 397 \\
(71.8)\end{array}$ & $\begin{array}{c}270 / 338 \\
(79.9)\end{array}$ & $\begin{array}{c}634 / 858 \\
(73.9)\end{array}$ & $\begin{array}{c}363 / 497 \\
(73.0)\end{array}$ & $\begin{array}{c}820 / 1197 \\
(68.5)\end{array}$ & $\begin{array}{c}408 / 464 \\
(87.9)\end{array}$ & $\begin{array}{c}696 / 850 \\
(81.9)\end{array}$ \\
\hline Diabetes & $\begin{array}{l}38 / 130 \\
(29.2)\end{array}$ & $\begin{array}{l}88 / 397 \\
(22.2)\end{array}$ & $\begin{array}{c}105 / 338 \\
(31.1)\end{array}$ & $\begin{array}{c}221 / 858 \\
(25.8)\end{array}$ & $\begin{array}{c}98 / 503 \\
(19.5)\end{array}$ & $\begin{array}{c}274 / 1207 \\
(22.7)\end{array}$ & $\begin{array}{c}138 / 465 \\
(29.7)\end{array}$ & $\begin{array}{c}231 / 848 \\
(27.2)\end{array}$ \\
\hline Dyslipidemia & $\begin{array}{l}77 / 130 \\
(59.2)\end{array}$ & $\begin{array}{c}223 / 397 \\
(56.2)\end{array}$ & N/A & N/A & $\begin{array}{c}345 / 497 \\
(69.4)\end{array}$ & $\begin{array}{c}740 / 1197 \\
(61.8)\end{array}$ & $\begin{array}{c}363 / 461 \\
(78.7)\end{array}$ & $\begin{array}{c}669 / 846 \\
(79.1)\end{array}$ \\
\hline Current smoker & $\begin{array}{c}27 / 130 \\
(20.8)\end{array}$ & $\begin{array}{l}99 / 397 \\
(24.9)\end{array}$ & $\begin{array}{c}91 / 338 \\
(26.9)\end{array}$ & $\begin{array}{c}234 / 858 \\
(27.3)\end{array}$ & $\begin{array}{c}130 / 497 \\
(26.2)\end{array}$ & $\begin{array}{c}273 / 1197 \\
(22.8)\end{array}$ & $\begin{array}{c}138 / 454 \\
(30.4)\end{array}$ & $\begin{array}{c}227 / 842 \\
(27.0)\end{array}$ \\
\hline $\begin{array}{l}\text { History of coronary } \\
\text { heart disease }\end{array}$ & $\begin{array}{l}15 / 130 \\
(11.5)\end{array}$ & $\begin{array}{l}78 / 397 \\
(19.6)\end{array}$ & $\begin{array}{l}51 / 287 \\
(15.1)\end{array}$ & $\begin{array}{c}218 / 858 \\
(25.4)\end{array}$ & $\begin{array}{c}104 / 497 \\
(20.9)\end{array}$ & $\begin{array}{c}363 / 1197 \\
(30.3)\end{array}$ & $\begin{array}{c}128 / 438 \\
(29.2)\end{array}$ & $\begin{array}{c}336 / 786 \\
(42.7)\end{array}$ \\
\hline
\end{tabular}

Data are mean (standard deviation, $\mathrm{SD}$ ) or $\mathrm{n} / \mathrm{N}(\%)$. 


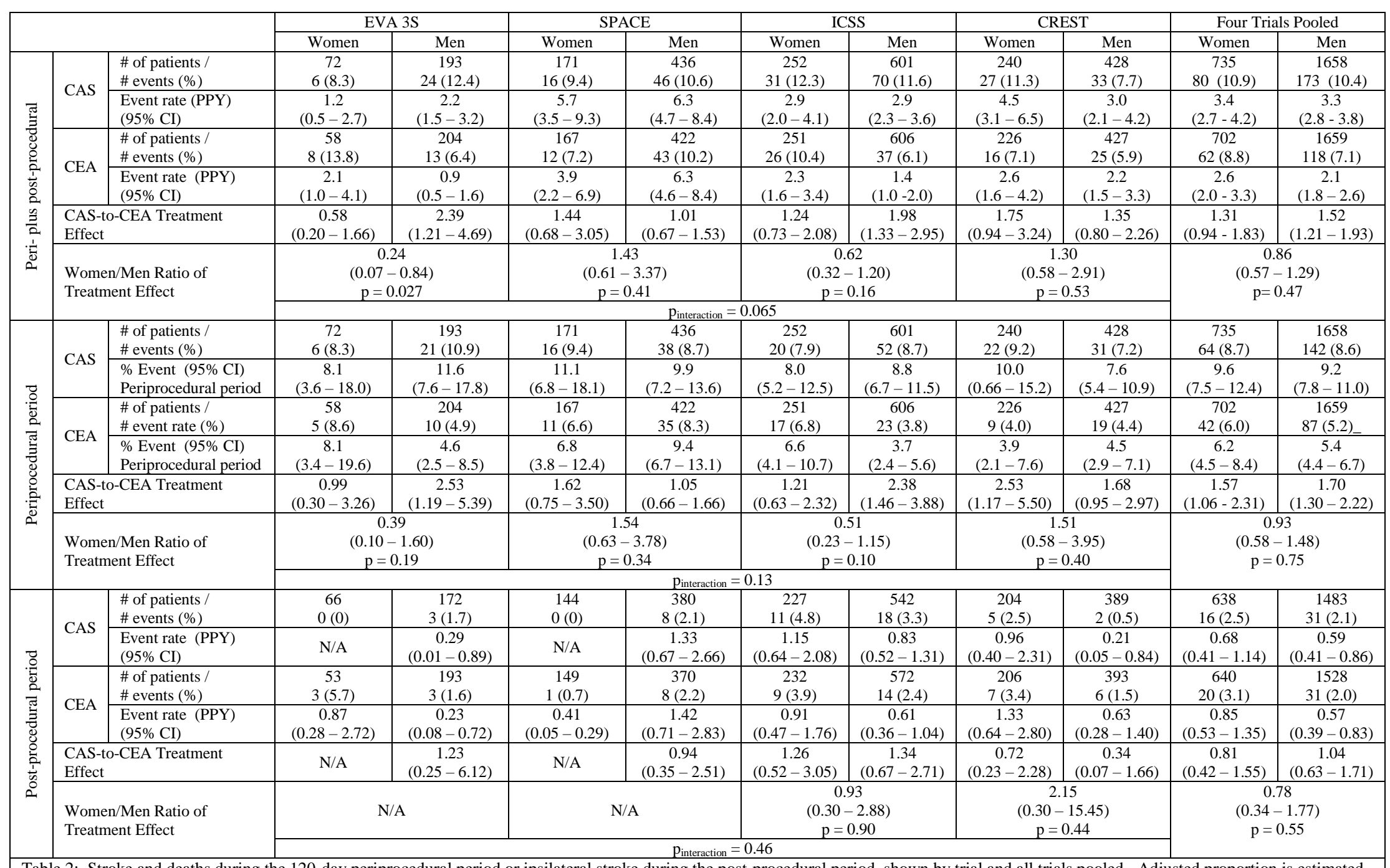

Table 2: Stroke and deaths during the 120-day periprocedural period or ipsilateral stroke during the post-procedural period, shown by trial and all trials pooled. Adjusted proportion is estimated as events per person-year exposure, and with adjustment for age group ( $<70$ vs. $70+$ ), and additionally adjusted for source trial in the pooled estimates. 